\title{
Exploring the cooperation-cooperation mode between scenic spots and tourism enterprises under the dual-channel tourism supply chain
}

\author{
Qinglin Luo, and Sheng Zhong* \\ Business School, Sichuan University, Chengdu 610064, China
}

\begin{abstract}
As the two most important nodes in the tourism supply chain, the competition, as well as the cooperation relationship between scenic spots and tourism enterprises, has a profound impact on the healthy development of the tourism industry. In this paper, we establish a dual-channel tourism supply chain model by making many assumptions about the operations of scenic spots and tourism enterprises. According to repeated game theory, we find that there is a certain trigger strategy for equilibrium strategy between scenic spots and tourism enterprises, and the cooperation-cooperation strategy is the optimal choice for scenic spots and tourism enterprises at this time.
\end{abstract}

Keywords: Tourism supply chain, Dual-channel model, Game theory.

\section{Introduction}

In recent years, tourism is booming worldwide because the living standards of people around the world have been improved, and governments around the world are strongly supporting and promoting it. Scenic spots as the regional places for tourism and their related activities, and tourism enterprises as the supporting enterprises and power engines of the tourism supply chain, both have very optimistic prospects for development [1].

Tickets are an important source of revenue for the tourism industry [2]. Scenic spots often adopt a dual-channel model to sell tickets. On the one hand, scenic spots sell tickets directly to tourists through their direct channels, and on the other hand, scenic spots also rely on tourism enterprises, such as tourist hotels, travel agencies, B\&Bs and other agency channels [3].

This paper focuses on the analysis of the cooperation-cooperation mode between scenic spots and tourism enterprises under dual channels, and then we explore the problem of equilibrium strategies for both.

\footnotetext{
*Corresponding author: szhong666@163.com
} 


\section{Assumptions and model}

In this paper, we select a two-channel tourism supply chain consisting of a scenic spot, a tourism enterprise, and tourists, where the tourism enterprise can be a tourist hotel, a travel agency, a local B\&B, etc. The scenic spot sells tickets through two channels, one is to sell directly to tourists through the scenic spot's channel, called the direct sales channel; the other is to sell tickets through the tourism enterprise, called the agency sales channel, as shown in Figure 1. Tourism enterprises design package tour products that include scenic spot tickets. Tourists choose one of the two channels by combining various factors and their own preferences.

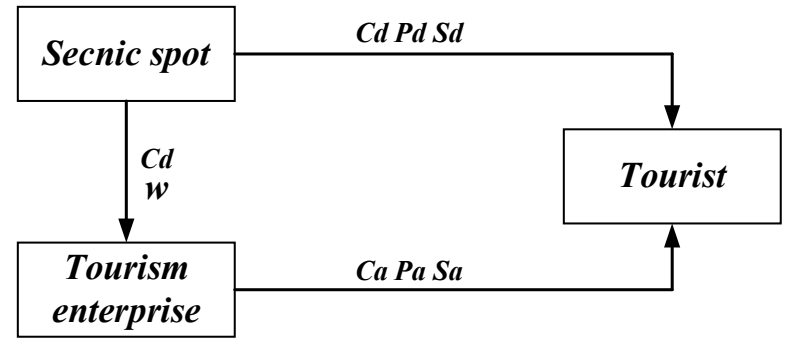

Fig. 1. Dual-channel tourism supply chain map.

The following are the main assumptions in the model.

Firstly, in this dual-channel tourism supply chain, the unit service cost incurred by the scenic spot for tourists is $c_{d}$. In direct sales channels, the unit price of tickets sold directly to tourists in the scenic spot is $p_{d}$; in agency sales channels, the scenic spot sells tickets to tourism enterprises at a unit wholesale price of $\omega$, and the additional unit service cost for the tourism enterprise to provide additional services to tourists is $c_{a}$. The unit price of package tour products sold by the tourism enterprise is $p_{a}$. Reasonable assumptions include $p_{a}>$ $p_{d}>0, p_{d}>c_{d}, p_{a}>c_{d}+c_{a}, p_{d} \geq \omega \geq 0$.

Secondly, similar to literature $[4,5,6]$, we suppose that the utility function of tourists is a function of the sales price $p$ of tourism products and the service experience $S$, where $u=$ $\theta S-p$, the $\theta$ represents the heterogeneous preference of different tourists, and $\theta \sim U(0,1)$. The quality of service experience brought to tourists by purchasing tickets for a single scenic spot through direct sales channels is recorded as $S_{d}$, and the quality of service experience brought to tourists by purchasing package tour products through the tourism enterprise is recorded as $S_{a}$. Reasonable assumptions include $S_{d}>c_{d}, S_{a}>c_{d}+c_{a}$. Obviously, there is a difference in experience between the two channels, we assume $S_{a}=(1+\lambda) S_{d}$, reasonable assumptions include $\lambda>0$. Furthermore, according to the principle of diminishing returns to scale, service improvements are often greater than additional costs, and enterprises always pursue greater price growth through certain improvements in functions. We assume in turn $\frac{s_{a}}{c_{d}+c_{a}}<\frac{s_{d}}{c_{d}}, \lambda S_{d}>c_{a}, \frac{p_{a}}{s_{a}}>\frac{p_{d}}{s_{d}}$.

Finally, we assume that the scenic spot and tourism enterprise have mutual complete information, under which the scenic spot first determines the direct ticket price $p_{d}$ and the wholesale price $\omega$, and the tourism enterprise then determines the price of the package tour product $p_{a}$.

According to the above assumptions, the profits of the scenic spot and tourism enterprise are:

$$
\begin{gathered}
\pi_{d}=\left(p_{d}-c_{d}\right)\left(\frac{p_{a}-p_{d}}{S_{a}-S_{d}}-\frac{p_{d}}{S_{d}}\right)+\left(\omega-c_{d}\right)\left(1-\frac{p_{a}-p_{d}}{S_{a}-S_{d}}\right) \\
\pi_{a}=\left(p_{a}-c_{a}-\omega\right)\left(1-\frac{p_{a}-p_{d}}{s_{a}-S_{d}}\right)
\end{gathered}
$$


Furthermore, the total profit of the entire tourism supply chain is:

$$
\pi_{t}=\pi_{d}+\pi_{a}=\left(p_{d}-c_{d}\right)\left(\frac{p_{a}-p_{d}}{s_{a}-S_{d}}-\frac{p_{d}}{s_{d}}\right)+\left(p_{a}-c_{d}-c_{a}\right)\left(1-\frac{p_{a}-p_{d}}{S_{a}-S_{d}}\right)
$$

\section{Profit solving under the model}

The so-called different strategy combinations, that is, both the scenic spot and tourism enterprise can choose cooperative or non-cooperative strategies, so there are four different strategy combinations between the scenic spot and tourism enterprise.

For example, under the noncooperation-noncooperation strategy combination, we can obtain that the scenic spot first decides the direct ticket price $p_{d}$ and the wholesale price $\omega$ to maximize $\pi_{d}$, and then the tourism enterprise decides the package tour price $p_{a}$ to maximize $\pi_{a}$. According to the inverse solution method, the scenic spots, tourism enterprises and the total profit are as follows:

$$
\begin{gathered}
\pi_{d_{1}}^{*}=\frac{2 \lambda\left(s_{d}-c_{d}\right)^{2}+\left(\lambda s_{d}-c_{a}\right)^{2}}{8 \lambda s_{d}} \\
\pi_{a_{1}}^{*}=\frac{\left(\lambda s_{d}-c_{a}\right)^{2}}{16 \lambda s_{d}} \\
\pi_{t_{1}}^{*}=\frac{4 \lambda\left(s_{d}-c_{d}\right)^{2}+3\left(\lambda s_{d}-c_{a}\right)^{2}}{16 \lambda s_{d}}
\end{gathered}
$$

By analogy, we can get the profit cases for the other three cases, and the payoff matrix is as follows (where, $X=\frac{\left(s_{d}-c_{d}\right)^{2}}{s_{d}}, Y=\frac{\left(\lambda s_{d}-c_{a}\right)^{2}}{\lambda S_{d}}$ ). Since the profits of each of the scenic spot and tourism enterprise under the combination of cooperation-cooperation strategy are related to $\omega$, we assume that the profit shared by the scenic spot is $K$ :

Table 1. Payoff matrix for scenic spots and tourism enterprises.

\begin{tabular}{|c|c|c|}
\hline $\begin{array}{c}\text { Nonterprise } \\
\text { Scenic spot }\end{array}$ & Non-cooperation & Cooperation \\
\hline Non-cooperation & $\frac{1}{4} X+\frac{1}{8} Y, \frac{1}{16} Y$ & $\frac{1}{4} X-\frac{1}{16 \lambda} Y, \frac{1}{4} Y$ \\
\hline Cooperation & $\frac{1}{4} X, \frac{1}{4} Y$ & $K, \frac{1}{4}(X+Y)-K$ \\
\hline
\end{tabular}

\section{Analysis of cooperation-cooperation strategy combinations}

From the above payoff matrix combined with repetition game theory, it can be found that if the result of the noncooperation-noncooperation strategy combination is efficient optimal in the Pareto sense, neither finite repetition nor infinite repetition can improve the equilibrium and benefit of this game. Therefore, to facilitate cooperation between scenic spots and tourism enterprises, the distribution of benefits under the cooperation-noncooperation strategy combination must first be made to satisfy:

$$
\frac{1}{4} X+\frac{1}{8} Y \leq K \leq \frac{1}{4} X+\frac{3}{16}
$$

Thus, the results of the noncooperation-noncooperation strategy combination lose their Pareto optimality. 
Further, we construct an infinite number of repeated games with a common trigger strategy for both sides: the first stage uses "cooperation", and at stage $t$, if the results of the first t-1 stages are "cooperation-cooperation", then we continue to use "cooperation", otherwise "non-cooperation" is applied. That is, both sides try to cooperate first in infinite repetitions of the game, and choose "cooperation" unconditionally for the first time, and insist on choosing "cooperation" if the other side also adopts the attitude of "cooperation". Once one side is found to choose "non-cooperation", the other side will always choose "noncooperation" to retaliate later.

We assume that the discount rate between the two stages of revenue is $r(0 \leq r \leq 1)$. For the scenic spot, in the first stage, tourism enterprise chooses "cooperation" strategy, the total benefit of its choice of "non-cooperation" strategy is:

$$
\frac{1}{4} X-\frac{1}{16 \lambda} Y+\frac{1}{1+r}\left(\frac{1}{4} X+\frac{1}{8} Y\right)+\frac{1}{(1+r)^{2}}\left(\frac{1}{4} X+\frac{1}{8} Y\right)+\cdots=\frac{1}{4} X-\frac{1}{16 \lambda} Y+\frac{1}{r}\left(\frac{1}{4} X+\frac{1}{8} Y\right)
$$

The total benefit of the "cooperation" strategy is:

$$
K+\frac{1}{1+r} K+\frac{1}{(1+r)^{2}} K+\cdots=\left(1+\frac{1}{r}\right) K
$$

Therefore, to ensure that the scenic spot always chooses the "cooperation" strategy in repeated games, the total "cooperation" benefit must not be smaller than the total "noncooperation" benefit, i.e., it must satisfy:

$$
\left(1+\frac{1}{r}\right) K \geq \frac{1}{4} X-\frac{1}{16 \lambda} Y+\frac{1}{r}\left(\frac{1}{4} X+\frac{1}{8} Y\right)
$$

Similarly, to ensure that tourism enterprise always chooses the "cooperation" strategy in repeated games, the total "cooperation" benefit must be no less than the total "noncooperation" benefit, i.e., it must satisfy:

$$
\left(1+\frac{1}{r}\right)\left[\frac{1}{4}(X+Y)-K\right] \geq \frac{1}{r}\left(\frac{1}{4} Y+\frac{1}{16} Y\right)
$$

From the above derivation, it can be seen that the combination of cooperation-cooperation strategy between the scenic spot and tourism enterprise, the value interval of $\mathrm{K}$ should be: $\left\{K \mid \frac{1}{4} X+\frac{1}{8} Y \leq K \leq \frac{1}{4} X+\frac{3}{16} Y, K \geq \frac{1}{4} X+\frac{1}{8} Y\left(\frac{1}{1+r}+\frac{1}{2 \lambda(1+r)}-\frac{1}{2 \lambda}\right) \& K \leq \frac{1}{4} X+\frac{3}{16} \frac{1}{1+r} Y\right\}$

Obviously, $\lambda$ always satisfies $\lambda>0$. Therefore, to make the value of $K$ is non-empty, it follows from the calculation: $0 \leq r \leq \frac{1}{2}$. Further, the value of $K$ can be obtained as $\left[\frac{1}{4} X+\frac{1}{8} Y, \frac{1}{4} X+\frac{3}{16} \frac{1}{1+r} Y\right]$, and the $K$ increases as $r$ decreases. In particular, when $r=0$, the $K$ is $\left[\frac{1}{4} X+\frac{1}{8} Y, \frac{1}{4} X+\frac{3}{16} Y\right]$; when $r=\frac{1}{2}$, the $K$ shrinks to $\frac{1}{4} X+\frac{1}{8} Y$. It is easy to know from the reality that the discount rate $r$ satisfies $0 \leq r \leq \frac{1}{2}$ in a shorter period. Thus, the equilibrium of benefit distribution between the scenic spot and tourism enterprise must be achieved.

Therefore, the above trigger strategy is the equilibrium strategy of the repeated game of cooperative and competitive strategies under the dual-channel supply chain model between scenic spots and tourism enterprises, which means that the cooperative-cooperative strategy is the optimal choice for scenic spots and tourism enterprises under this trigger strategy.

\section{Conclusion}

In this paper, we establish the dual-channel supply chain model of scenic spots and tourism enterprises. In addition, we get the profits of four different strategic combination models under the condition of perfect information of both by the inverse solution method, and further analyze the cooperative-cooperative strategy between them according to the repeated game theory to find the equilibrium strategy of both sides of the cooperative-cooperative strategy under the appropriate trigger strategy, which is also the optimal choice. 


\section{References}

1. Grigorescu A, Lincaru C, Pirciog S, et al. Mapping post crises the European job growth in travel agencies and tour operator reservation services[J]. Economic ResearchEkonomska Istraživanja, 2020: 1-19.

2. Wu, W., Zhang, L., \& Qiu, F. (2017). Determinants of tourism ticket pricing for ancient villages and towns: Case studies from Jiangsu, Zhejiang, Shanghai and Anhui provinces. Tourism Management, 58, 270-275.

3. Li Y, Yang L, Han S, et al. Modeling intra-destination travel behavior of tourists through spatio-temporal analysis[J]. Journal of Destination Marketing and Management, 2019, 11 .

4. Xiaolong Guo, Lina He. Tourism Supply-Chain Coordination: The Cooperation between Tourism Hotel and Tour Operator. 2012, 18(6):1361-1376.

5. Junfeng Dong. Comparative Analysis of Underdeveloped Tourism Destinations' Choice of Cooperation Modes: A Tourism Supply-Chain Model. 2012, 18(6):1377-1399.

6. Harewood S . Coordinating the tourism supply chain using bid prices[J]. Journal of Revenue \& Pricing Management, 2008, 7(3):266-280. 